\title{
The Time Diversification Controversy: An Analysis of the Italian Financial Market
}

\author{
Agnese Sechi \\ University of Genoa \\ Italy \\ Gabriele Cardullo \\ University of Genova \\ Department of Economics and Business \\ Via Vivaldi 5, 16126 Genova, Italy
}

\begin{abstract}
.
Does the risk of an investment change with its timehorizon? In this article we put to test the competing claims presented by the literature on the so-called time diversification controversy. Using data from the Italian financial market of the last twenty years, we look at the evolution of different measures of risk as we extend the investment period. Our results seem to confirm Samuelson's view, that, under certain conditions, the riskiness of an investment increases with the time horizon.
\end{abstract}

Keywords: time diversification controversy; measures of risk; returns on equities.

\section{Introduction}

At least since Samuelson (1963)'s seminal contribution, economists have debated about the so-called time diversification controversy. Does the risk of an investment change as its time horizon increases? In that paper and in subsequent ones (see Samuelson, 1969 and 1971), Samuelson argues that the allocation of risky assets is independent of time and determined only by risk tolerance1.

The theory on which Samuelson' thesis is based is built on three pillars and it is expressed in a multi-period context. The pillars are: the investor shows a constant relative risk aversion (CRRA); returns follow a random walk; wealth depends exclusively on returns.

Bodie (1991 and 1995) challenges this view, by considering a new measure of risk. More specifically, the risk of an investment corresponds to the cost of an insurance against the absolute risk of shortfall. This is defined as the probability that the expected returns of a portfolio at maturity is lower than a certain threshold (usually, the risk-free rate). Using the Black-Scholes-Merton model for option pricing (see Black and Scholes, 1973), Bodie then shows that the price of such an insurance increases with time. This is valid both under the hypothesis that stock returns follow a random walk, and under the assumption that they take a mean-reverting process (according to some economists, this is the reason why stocks would be less risky for investors with a long time horizon). The idea of identifying the market value of risk as the price

1Samuelson famously recounts a bet offered to one of his colleagues, in which he would have either won $200 \$$ or lost $100 \$$ with equal probabilities. The colleague refused, adding that he would have agreed to bet if the same lottery was repeated 100 times. For Samuelson, this answer lies on a clear misinterpretation of the law of large numbers. Dividing the sum at stake in 100 independent lotteries makes a risk averse individual better off, not playing the same lottery 100 times. However, the choice of Samuelson's colleague may be consistent with theories on preferences different from the expected utility one. See Chew and Epstein (1988).

of put option in a Black-Scholes-Merton formula is then criticized by Cohen et al. (1996) and Dempsey et al. (1996).Studies in behavioral finance have also addressed the issue of tempo-ral diversification (see for instance Olsen, 1998, and Kritzman, 1994). Although, as Bianchi et al. (2016) point out, behavioral economists do not propose a new analytical framework to understand the time di-versification controversy, they single out some critical points of more standard approaches. Olsen et al. (1998) focus on how the concept of investment risk differs according to category of people one analyzes. In their study, they compare the results of a survey conducted both on individuals whose wealth is affected by the investment management decisions and portfolio professional managers (a group randomly selected from the directory of the Chartered Financial Analysts). 
Unlike the other group of individuals, the main risk for such managers is to underperform with respect to their competitors. Such a difference in attitude explains how the same assets are evaluated differently by the two categories of people.The lack of a common definition for risk and risky assets is also emphasized by Olson and Khaki (1998). They argue that the concept of risk may be considered an "emergent" phenomenon, whose measurement is contingent on a particular environment. For them, the basic foundations of the expected utility theory, namely that expected utility is just the sum of the products of the outcomes and probabilities, may not correctly represent the way in which investors think about uncertainty. Rather, they suggest an additive model of risk, in which expected loss is the sum of its probability and the negative outcome. In a similar vein, Chew and Epstein (1989) show that time diversificationmay be consistent with a theory of preferences in which a decumulative weighted function takes the place of the standard expected utility approach.

In this paper, we consider several risk measures and put them to test, by looking at the Italian financial market. In particular, we look at the monthly returns of several indexes, representing risky assets, and the return of a ten-year Treasury bond. For each index we calculate different risk measures, namely the standard deviation, semi standarddeviation, $\mathrm{VaR}$, and shortfall risk, considering them over various time horizons (1, 5, 10,15 and 20 years). Our results seem to confirm the validity of the Samuelson original insight. The risk does not decrease as the time horizon of the investment gets longer. Actually, data show a small but significant increase of the risk for all the indicators put in exam.

The paper is organized as follows. Section 2 presents the data. Section 3 illustrates the various measures of risk and the corresponding results. Section 4 concludes.

\section{Data}

We consider the monthly returns of the three most important indexes of risky assets in the Italian market:

- FTSE MIB. It is the main reference index of the Italian stock markets. It incorporates the shares of 40 Italian companies listed on the MTA (Mercato Telematico Azionario) with greater capitalization, liquidity and free float. The FTSE MIB index is weighted according to market capitalization after adjusting the components based on the free float.

- FTSE Italia All-Share. The Index comprises of all constituents in the FTSE MIB, FTSE Italia Mid Cap and FTSE Italia Small Cap indexes. FTSE Italia Mid Cap consists of the top 60 shares ranked by company full market capitalization i.e. before the application of any investability weightings outside the FTSE MIB Index which qualify after the application of the liquidity and free floats screens. FTSE Italia Small Cap captures the performance of all other small shares outside the FTSE MIB Index and FTSE Italia Mid Cap Index which qualify after the application of the liquidity and free floats screens.

- FTSE Italia Star: the index includes shares present in the Star segment of the MTA market. The Star subset is dedicated to midsize companies with a capitalization of less than 1 billion euros and that comply with some requirements about trans-parency, liquidity and corporate governance.

For the risk-free asset, we analyze the annual rates of return on a monthly basis for ten-year Buoni Ordinari del Tesoro (BTP). These are Government debt securities with a coupon paid every six months. Data on data FTSE MIB and FTSE Italia All-Share are collected using Datatream, while we use Yahoo Finance for those of FTSE Italia Star. Data ontenyear BTPs come from the database of OECD-iLibrary main economic publications.

For each time horizon the value considered as a quantity of risk is calculated by computing the simple average of this quantity in the different periods in which it is possible to subdivide the data sample. More specifically, the simple average of the standard deviation, semi-standard deviation, shortfall risk, and VaR of each year is analysedfrom 1999 to 2019, of every 5 years for the periods $2019-2014,2014-2009,2009-2004,2004-1999$ and every 10 years for the periods 2019 - 2009, 2009 - 1999; for the horizons of 15 and 20 years the period is considered entirely (first data is July 1999, last July 2019). This is possible in a complete way for the FTSE MIB and for the ten-year BTPs, whose data for twenty years are available; for the other indexes a time horizon of about sixteen and a half is considered In the tables we report 20 years to represent the maximum horizon.

\section{Risk Measures And Results}

\subsection{Standard deviation.}

The first risk measure analyzed is the standard deviation. Table 1 illustrates the results. Numerous studies in the literature deal with the standard deviation of annualized returns as a measure of risk; many scholars have shown that, as the time horizon increases, the risk decreases. However, in this analysis the results seem to confirm Samuelson's thesis. The standard deviation for the very short-term horizon (1 year) is lower for all the stock indexes and for BTPs than the one computed for a 20 years investment. We can also see that for all assets the risk increases from a time horizon of 1 
year to one of 5 years. From 5 years on, results are not the same for all the indexes: for the FTSE MIB the standard deviation decreases progressively, from 5 to 10 years and from 10 to 15 years, and then it grows in the maximum period considered (+0.00163). For the FTSE All Share there is instead a decrease in the standard deviation from 5 to 20 years $(-0.00141)$, which however remains at a higher level than the one calculated at 1 year. FTSE Star hovers a bit around the value obtained at the 5-year horizon. The standard deviation for the BTP,on the other hand, remains roughly the same for all the time horizons taken in exam.

To sum up, for all the indexes it is clear that there is a positive trend between the 1 year horizon and the 5-year horizon. After the 5-year horizon, the standard deviation for FTSE Italia All Share remains practically constant, except for a small drop from 15 years, while for the FTSE MIB and the FTSE Italia Star movements are less regular.

Notice also that the FTSE MIB exhibits the highest values, followed by the FTSE Italia All Share and the FTSE Italia Star.

Recall that FTSE MIB includes the stocks of companies with the largest capitalization in the market. So, such a result is in contrast with the so-called size eff ect, according to which larger firms have higher stock returns and lower volatility (see Ang et al. 2009). A possible motivation for this anomaly could depend on the dire macroeconomic conditions of Italy in the last two decades, a period when large firm, especially in the financial sector, suff ered most.

\subsection{Semi-Standard Deviation.}

We turn the semi-standard deviation, in which only the sub-average returns are considered. Such a measure is interesting and useful to understand how volatility can vary in a rather negative scenario, below the mean.

Looking at the Table 2, we can see how the conclusions reached are the same as those of the analysis carried out previously for the stan-dard deviation, although obviously with lower average values. Also in this case the risk increases significantly from the horizon to 1 year tothat at 20 years, especially for the FTSE Star (FTSE MIB +0.00784, FTSE All Share +0.00758, FTSE Star +0.00887 and BTP +0.00056). Furthermore, we note again that for all the assets there is a preponderant growth of the risk measure from the annual to the five-year horizon $(+0.00793$ for the FTSE MIB,+0.00847 for the FTSE All Share, +0.00926 for the FTSE Star and finally +0.0001 for the BTP).

Notice also that the volatility of the FTSE MIB index first grows and then remains roughly constant (from 0.03983 to 0.03951 and 0.03995). The FTSE Italia All Share and the FTSE Star have a very similar trend. The movement for the BTP again shows a gradually increasing behavior as the time horizon gets longer. Of course, the semi-standard deviation of the BTP is much lower than that of the indexes, due to its risk-free nature. Conversely, the FTSE MIB is the index with the highest risk level, followed by the FTSE All Share and the FTSE Star. This is in line with what already discussed the previous paragraph. The largest and most capitalized companies seem more volatile even if we turn the attention only to bad scenarios. We can try to explain this by framing the result in a scenario of economic recession, which may have involved this type of anomaly (in contrast with the canonical literature already mentioned). In conclusion, even analyzing the standard semi-deviation it is possible to conclude that the risk increases with the time horizon.

\subsection{Var.}

Value at risk is an important risk measure that indicates the maximum potential loss (deriving from holding an asset) in which it is possible to incur in relation to a given confidence level and a defined time horizon. Unlike other risk measures, it allows to aggregate the risks of different positions and to provide an estimate of potential losses. The reference confidence level usually varies between $90 \%$ and $99.9 \%$, depending on the specific needs of the institution that uses this measure or the regulatory obligations imposed by the competent Authorities. In formulas:

$\operatorname{Prob}(\mathrm{L} \geq \mathrm{VaR})=1-\alpha$

or

$\operatorname{Prob}(\mathrm{L}<\mathrm{VaR})=\alpha$,

Where $\mathrm{L}$ indicates the loss, $\alpha$ the confidence level. For this study we assume that data are normally distributed and we use a confidence level of $90 \%$. We compute the VaR via the method normal / variance-covariance. The assumption that returns follow a normal distribution may be judged plausible by the fact that the indexes are very large baskets of securities.The computations are made by referring only to the returns. So returns are in percentage terms and not in absolute terms. Table 3 shows that all the indexes experience a substantial increase in the potential loss once the interval passes from 1 year to 5 years $(+0.0048$ for the FTSE MIB, +0.00697 for the FTSE All Share,+0.00651 for the FTSE STAR). For time horizons greater than 5 years, there is a decrease of the VaR in absolute terms.

In particular, for the FTSE MIB it can be seen that the potential loss decreases from 10 to 15 years and then it increases, returning very close to the previous values of 5 and 10; comparing the very short-term horizon with the long one, we notice that there is an important increase of +0.00461 .The trends of FTSE All Share and FTSE Star are similar; 
both see a decrease after the 5 years interval, followed by a growth, which is followed by a slight decrease. There is an increase of the values, alwaysin absolute terms, from the horizon from 1 year to 20 years of +0.00415 and +0.00475 respectively for the first and second index.

With respect to the ten-year BTP, there are no negative returns, and therefore there are very low returns which decrease as the time horizon rises, except for a slight increase going from 15 to 20 years.

In general, the result that emerges is that the index with the high-est VaR is the FTSE MIB, followed by the FTSE Italia All Share. The scenario is consistent with what emerged in the study of the semi-standard deviation. When we focus on the negative outlook, the FTSE MIB seems to be most risky, followed by the FTSE All Share (a consequence of the fact that it contains the FTSE MIB), and by the FTSE Star. So, not just the volatility (also of the below-average yields) seems to be higher for large-cap companies than the smaller ones, even the maximum expected losses in the $90 \%$ of cases seem to be higher.

Even using a VaR approach, the result is clear: the risk seems to grow with the time horizon.

\subsection{Shortfall Risk.}

The risk of shortfall is defined as the probability of not reaching a certain threshold yield. This threshold yield often matches in the literature with the risk free rate yield. For this analysis we use the ten-year BTP was used as a risk-free asset, so to compute the diff erences in returns between the index and the BTP for each time horizon. The shortfall risk is then calculated by contrasting the number of months in which these diff erences are negative (i.e. when the index underperforms compared to the BTP), with the total number of months within the overall period considered.

Several points emerge looking at the data in Table 4. First, the risk increases for the FTSE MIB and the FTSE All Share with the length of the time horizon (with the sole exception of the risk at 15 years, which is slightly higher than that of the maximum horizon for the FTSE Italia All Share). On the other hand, the shortfall risk for the FTSE Star index exhibits a different behavior, with the peak at 1-year interval. However, if we observe the risk trend from the 5-year horizon, we can see how it gradually increases as the time horizon rises.

In conclusion, even using the risk of shortfall as a measure, it seems to grow as the time horizon increases.

\section{Conclusions}

The idea that the risk decreases with the rise of the time horizon has been at the center of the debate of temporal diversification. Is risk decreasing with time? From the first studies of Samuelson, many theories have been developed, with competing viewpoints and based on different orderings of preferences and different concepts of risk. In this paper we choose various risk measures and we analyze the risk-time horizon link for each one. What emerges is a coherent framework for all assets and substantially for all risk measures: the risk tends to grow as the time horizon increases. We find that the standard deviation, the semi-standard deviation, the VaR, and the risk of shortfall show an increasing trend as the time horizon passes from the 1 year to the 20 years. The FTSE Italia Star is an exception for what concerns the risk of shortfall. In particular, the risk increases more significantly from the one-year horizon to the five-year horizon. So, at least as concerns the Italian financial data of the last twenty years, Samuelson's claims seem empirically confirmed.

\section{References}

Ambachtsheer, K.P., 1989, The persistence of investment risk, Journal of Port-folio Management, 1, pp. 69-71.

Ang, A., Hodrick, R. J., Xing, Y., Zhang, X., 2009 High idiosyncratic volatilityand low returns: International and further U.S. evidence, Journal of FinancialEconomics, 91(1), pp 1-23.

Bennyhoff, D.G., 2009, Time Diversification and Horizon-Based Asset Alloca-tions, Journal of Investing, 18, pp. 4552.

Bianchi, R.J., Drew, M.E., Walk, A.N., 2016, The Time Diversification Puzzle:A Survey, Financial Planning Research Journal, pp. 12-48.

Black, F., Scholes, M., 1973, The Pricing of Options and Corporate Liabilities, Journal of Political Economy 81 (3), pp 637-654.

Bierman, H., 1997, Portfolio Allocation and the Investment Horizon, Journal of Portfolio Management, 23, pp. 51-55.

Bodie, Z., 1991, Shortfall Risk and Pension Fund Asset Management, Financial Analysts Journal, 47, pp. 57-61.

Bodie, Z., 1995, On the Risks of Stocks in the Long Run, Financial Analysts Journal, 51, pp. 18-22.

Bodie, Z., Kane, A., Marcus, A.,J., 1998, Investments, McGraw-Hill, Boston.

Booth, L., 2004, Formulating retirement targets and the impact of time horizonon asset allocation, Financial Services Review 13, pp. 1-17. 
Chew, S.H., Epstein, L.G., 1988, The law of large numbers and the attractivenessof compound gambles, Journal of Risk and Uncertainty 1, pp. 125-132.

Chew, S. H., Epstein, L. G, 1989, The Structure of Preferences and Attitudes to-wards the Timing of the Resolution of Uncertainty, International Economic Review,30(1), pp 103-117.

Cohen, G.M., de Fontenay, P., Gould, G.L., Sirera, M.C., Bodie, Z., 1996, Long-Run Risk in Stocks, Financial Analysts Journal, 52, pp. 72-76.

Davis, R., 2014, The Myth of Time Diversification. Web site:https://www.soa.org/essays-monographs/investfallacies/inv-ebook-2014-davis-the-myth.pdf.

Dempsey, M., Hudson, R., Littler, K., Keasey, K., 1996, On the Risk of Stocksin the Long Run: A Resolution to the Debate?, Financial Analysts Journal, 52, pp.57-62.

Fabozzi, F.J., Focardi, S.M., Kolm, P.N., 2006, A Simple Framework for TimeDiversification, Journal of Investing 15, 8-17.

Ferguson, R., Leistikow, D., 1996, On the Risks of Stocks in the Long Run: AComment, Financial Analysts Journal, 52, pp. 67-68.

Fisher, K.L., Statman, M., 1999, A Behavioral Framework for Time Diversifica-tion, Financial Analysts Journal, 55, pp. 88-97.

Gollier, C., 2000, Time diversification, liquidity constraints, and decreasing aversion to risk on wealth. Web site:https://www.sciencedirect.com/science/article/abs/pii/S0304393202001733.

Kritzman, M.P., 1994, What Practitioners Need to Know... About Time Diver-sification, Financial Analysts Journal, 50, pp. 14-18.

Lu, R., Yang, C., Wong, W., 2018, Time Diversification: Perspectives from theEconomic Index of Riskiness. Web site:https://mpra.ub.uni-muenchen.de/89167/.

Mehra, R., 2008, Handbook Of The Equity Risk Premium, Elsevier Science.

Merrill, C., Thorley, S., 1997, Time Diversification and Option Pricing Theory:Another Perspective': Response, Journal of Portfolio Management, 23, pp. 61-63.

Mukherji, S., 2002, Stocks, Bonds, Bills, Wealth, and Time Diversification, Jour-nal of Investing, 11, pp. 39-52.

Olsen, R.A., 1998, Behavioral Finance and Its Implications for Stock-PriceVolatility, Financial Analysts Journal, 54, pp. 10-18.

Olsen, R.A., Khaki, M., 1998, Risk, Rationality, and Time Diversification, Fi-nancial Analysts Journal, 54, pp. 58-63.

Olsen, R.A., 1997, Investment Risk: The Experts’ Perspective, Financial Ana-lysts Journal, 53, pp. 62-66.

Samuelson P.A., 1963, Risk and Uncertainty: A Fallacy of Large Numbers', Sci-entia, 98, pp. 108-113.

Samuelson, P.A., 1969, Lifetime Portfolio Selection By Dynamic Stochastic Pro-gramming, Review of Economics and Statistics, 51, pp. 239-246.

Samuelson, P.A., 1971, The "Fallacy" of Maximizing the Geometric Mean inLong Sequences of Investing or Gambling, Proceedings of the National Academy ofSciences, 68, pp. 2493-2496.

Statman, M., 2004, The Diversification Puzzle, Financial Analysts Journal, 60, pp. 44-53.

Strangeland, D.A., Turtle, H.J., 1999,Time Diversification: Fact or Fallacy, Journal of Financial Education, 25, pp. 113.

Strong, N., Taylor, N., 2001,Time Diversification: Empirical Tests, Journal of Business Finance \& Accounting, 28, pp. 263-302.

Taylor, R., Brown, D.J., 1996, On the Risk of Stocks in the Long Run: A Note, Financial Analysts Journal, 52, pp. 6971.

Thorley, S.R., 1995, The Time-Diversification Controversy, Financial Analysts Journal, 51.

Warwick, B., 2003, The Handbook of Risk, Wiley Finance, New Jersey. 


\begin{tabular}{|c|c|c|c|c|}
\hline Horizon & FTSE MIB & FTSE ALL SHARE & FTSE STAR & BTP \\
\hline 1 year & 0.05656 & 0.05191 & 0.04411 & 0.00026 \\
\hline 5 years & 0.06031 & 0.05654 & 0.04928 & 0.00050 \\
\hline 10 years & 0.06023 & 0.05687 & 0.04667 & 0.00086 \\
\hline 15 years & 0.05853 & 0.05639 & 0.04938 & 0.00107 \\
\hline 20 years & 0.06016 & 0.05499 & 0.04786 & 0.00107 \\
\hline
\end{tabular}

TABLE1.Standad Deviation

\begin{tabular}{|l|l|l|l|l|}
\hline Horizon & FTSE MIB & FTSE ALL SHARE & FTSE STAR & BTP \\
\hline 1 year & 0.03211 & 0.02952 & 0.02695 & 0.00014 \\
5 years & 0.04004 & 0.03799 & 0.03621 & 0.00024 \\
10 years & 0.03983 & 0.03521 & 0.03185 & 0.00037 \\
15 years & 0.03951 & 0.03798 & 0.03691 & 0.00058 \\
20 years & 0.03995 & 0.03711 & 0.03582 & 0.00070 \\
\hline
\end{tabular}

TABLE2.Semi-standard deviation

\begin{tabular}{|l|l|l|l|l|}
\hline Horizon & FTSE MIB & FTSE ALL SHARE & FTSE STAR & BTP \\
\hline 1 year & -0.07246 & -0.06464 & -0.04817 & 0.00295 \\
5 years & -0.07726 & -0.07161 & -0.05468 & 0.00265 \\
10 years & 0.07716 & -0.07017 & -0.04854 & 0.00219 \\
15 years & 0.07450 & -0.07142 & -0.05480 & 0.00163 \\
20 years & -0.07707 & -0.06879 & -0.05292 & 0.00192 \\
\hline
\end{tabular}

TABLE3. VaR

\begin{tabular}{|l|l|l|l|l|l|}
\hline Index & Horizon max & 15 years & 10 years & 5 years & 1 year \\
\hline FTSE MIB & 0.48333 & 0.46666 & 0.46666 & 0.43333 & 0.33333 \\
FTSE ALL SHARE & 0.46733 & 0.47222 & 0.46666 & 0.43333 & 0.33333 \\
FTSE STAR & 0.38805 & 0.37777 & 0.36666 & 0.33333 & 0.41666 \\
& & & & & \\
\hline
\end{tabular}

TABLE 4. Shortfall risk 